\title{
The Membrane Receptor Complex Regulating Induction and Clonal Expansion of Normal Murine B Lymphocytes
}

\author{
Stina Forsgren, Bernhard Kleine, Grgur Pobor, \\ Carlos Martinez-A., Luciana Forni, and \\ Antonio Coutinho
}

\author{
From the Department of Immunology, Umea University, \\ Umea, Sweden; the Laboratory of Immunobiology, Pasteur \\ Institute, Paris, France; and the Basel Institute for \\ Immunology, Basel, Switzerland
}

\begin{abstract}
Induction of resting B lymphocytes results from the interaction of competent ligands or helper cells with "triggering receptors." Subsequent clonal expansion and performance are thought to be regulated by the interaction of selective growth or maturation factors with specific receptors on induced B cells. A set of membrane molecules of B lymphocytes, including IgM, IgD, IA, IE, lipopolysaccharide receptors, receptors for Fc and $\mathrm{C} 3 \mathrm{~b}$, and other non-immunoglobulin structures recognized by some antiidiotypic antibodies, display ligand-induced relationships. Functional studies also indicate that this group of molecules functions as a complex that regulates delivery of inductive signals, the expression of growth and maturation receptors, and/or the outcome of the interactions of these receptors with the corresponding factors.
\end{abstract}

Network concepts [1] have radically altered classic perspectives of the immune system. Defense against infection is no longer the only or even the major aspect in immune physiology: the immune system is turned inward and includes images of all molecular patterns. No distinction can be made between the epitopes of "self" and "nonself." In spite of this profound conceptual revolution, some properties of bacterial products in their interaction with lymphocytes make it unescapable to conclude that the immune system started, at least in part, by being a protective, antiinfectious organ. The remnants of this evolutionary past are numerous and quite spectacular [2-4]. Perhaps the most widely analyzed is the ability of lipid A to stimulate a large fraction $(10 \%-50 \%)$ of all $B$ lymphocytes in the mouse.

The mere consideration of this phenomenon is sufficient for us to conclude that "internal images" of lipid A do not exist in vertebrates and to segregate properties of lipid $A$ from the universe of the epitope and the molecular basis of those reactions from that of antibody recognition. In fact it has been established that $\mathrm{B}$ lymphocyte reactivity to

The work summarized in this paper was supported in part by the Swedish Medical Research Council.

We thank Ms. C. Bergman and Ms. J. Badella for typing the manuscript.

Please address correspondence to Dr. Stina Forsgren, Department of Immunology, University of Umeå, S-901 85 Umeå, Sweden. lipid A is controlled by a locus on chromosome 4 $[5,6]$ that appears to determine the expression of membrane molecules that specifically bind lipid A and are competent to generate triggering signals [7]. The study of the biochemistry of those putative lipid A receptors has been haltered by the difficulty in preparing monospecific reagents. On the other hand, recent progress in the analysis of B cell activation, growth, and maturation provide new perspectives for the role of "triggering" or "mitogen" receptors in B cell physiology. We shall briefly discuss this progress here.

\section{Physiology of B Cell Activation and Clonal Performances}

The analysis of $\mathrm{B}$ cell responses stimulated by helper $\mathrm{T}$ lymphocytes has revealed three distinct phases: (l) induction of resting B lymphocytes to a state of reactivity to nonspecific factors [8], which requires direct cell-to-cell interactions and participation of IA and IE molecules recognized on the responding $B$ cell membrane by allospecific [9] or major histocompatibility complex (MHC)-restricted helper cells [10]; (2) proliferation of "induced" B cells upon interaction of cell type-specific growth factors (BCGF) with appropriate receptors, which are not expressed by resting cells [11]; and (3) maturation of proliferating B cells, regulated by nonspecific factors (BCMF) competent for stimulating increased rates of synthesis and secretion of immunoglobulins [12, 13]. At 
least one type of BCGF is produced by $\mathrm{T}$ lymphocytes, and although definitive evidence is still lacking in this respect, helper cells appear to be competent in the production of maturation factors as well [12].

The fact that there are stringent requirements for nonspecific factors in B cell responses, although not surprising in light of some current concepts of lymphocyte activation [2-4], raised similar questions for mitogen-activated systems. B cell responses to lipopolysaccharide (LPS), for example, had previously been described as independent of $T$ cells and macrophages [14, 15], a finding that implies lipid A could function directly as an inducer, a growth factor, and a maturation signal for normal B lymphocytes. Improved conditions for accessory-cell depletion, however, have suggested to a number of investigators [16-19] that both LPS-dependent growth and maturation of $B$ lymphocytes is macrophage dependent. In turn, this conclusion would imply that LPS-activated macrophages are competent to produce growth and maturation factors, perhaps distinct from those with a $\mathbf{T}$ cell origin. It is also clear, however, that LPS-activated $B$ cell blasts are reactive to both BCGF and BCMF derived from $T$ cells [11], a fact demonstrating that $\mathrm{B}$ lymphocyte growth can be brought about by independent pathways.

On the other hand, an absolute macrophage dependence of LPS-induced response must be considered with reservations. First of all, in those experiments, there are no indications on selective losses during purification of B cells that presumably could respond directly to LPS by proliferation. The available results only indicate that some B lymphocyte subsets require macrophages to proliferate in LPS-stimulated cultures. Secondly, it is impossible to distinguish, in the activity of macrophages, simple pleotropic or "filler" effects from a specific function, such as the production of a growth factor. Finally, several B cell lymphomas, cloned and maintained in vitro in the absence of any other cell type, have been shown to respond to LPS with an increase in proliferation and maturation.

These recent experiments, however, have contributed one general conclusion, namely that induction of resting B cells is accessory-cell independent, even if the subsequent phases in the response are not. Before these latter details are settled, therefore, we shall consider here only the role of lipid A receptors on the induction step in B lymphocyte responses and its regulation by other membrane molecules.

\section{A Molecular Complex on the B Lymphocyte Membrane}

We and others have observed ligand-induced interactions between several independent B cellmembrane molecules [20-25]. These interactions are demonstrated either in "cocapping" experiments or by the consequences of specific ligand binding to a given molecule, in the absence of redistribution, on the availability of other receptors that can be either inhibited or enhanced. Such interactions have delineated a complex that includes antibody receptors of both IgD and IgM classes, class II MHC products (both IA and IE molecules), LPS receptors, receptors for Fc and C3b, and other less-defined structures, such as putative products of the Mls locus and those recognized by some antiidiotypic antibodies. Most interestingly, there is a definite position of the various molecules in the complex, and there appears to exist a hierarchy or directionality of interactions, as shown by the analysis of the different combinations. Finally, the general properties of this complex and the type of specific interactions observed change with the stage of activation of the cell, in particular early after exposure to LPS.

These observations acquire particular importance because the functional counterpart of those interactions can be demonstrated readily. Thus, antibodies against several components of this complex interfere with or modulate the ability of LPS to induce B lymphocytes. Furthermore, the kinetics of LPS-dependent induction of reactivities to growth factors is closely paralleled by the shift from resting- to activated-type interactions as well as by the loss of the ability of the same antibodies to modulate responses. In this respect, the recent finding of Herrlich et al. [26] - that synthesis of a protein currently designated "invariant I-chain" is drastically reduced in activated B lymphocytes may be of value for a complete understanding of this process. More recent experiments would actually suggest a role for Ii in maintaining the topography in the complex and the regulation of Ii synthetic rates by LPS (P. Herrlich, L. Forni, and A. Coutinho, unpublished observations). To be confirmed, these indications would ascribe a pri- 
mary role for those multimolecular interactions at the B lymphocyte membrane in the triggering process. It follows that the mere binding of lipid A to its specific receptor might not be sufficient for inducing $\mathbf{B}$ cells in the absence of a chain of reactions involving the other components in the complex, as suggested by the inhibition observed with anti-IgM [27] and anti-Ia antibodies [28] directed to various domains of either IA or IE molecules [29]. In this respect, it should be noted that, depending on the relative position of each of these molecules in the complex, the effects of ligand binding vary in accordance with the type of inductive signals used. For example, anti-IgD is not inhibitory of LPS-induced responses [30] in contrast to IgM, which, however, fails to inhibit helper celldependent activation [31]. These observations also demonstrate that some of the components in the complex are inductive or triggering receptors, such as the lipid A receptor [7] or IA and IE [9], while others, such as $\operatorname{IgD}$ or $\operatorname{IgM}$ - at least in our own experience-are not [32].

The model for $\mathrm{B}$ cell activation presented here offers an explanation for apparently "abnormal" induction via ligand binding to nontriggering receptors as well as for many observations on the synergy between ligands of different specificities. Thus, under selected experimental conditions that modulate interactions in the complex, the availability of competent triggering receptors might increase above threshold levels and reveal or enhance the activity of inducing ligands present at subliminal levels. It is likely, on the other hand, that initial inductive reactions simply lead to the functional expression of receptors for nonspecific growth and maturation factors. The selective expression of receptors for one or the other type of factors is also likely to be regulated via that complex which consequently, controls the balance between proliferation and terminal maturation in activated B lymphocyte clones.

\section{References}

1. Jerne NK. Towards a network theory of the immune system. Ann Immunol (Paris) 1974;125C:373-89

2. Coutinho A. The theory of the "one nonspecific signal" model for B cell activation. Transplantation Reviews 1975;23:49-65

3. Coutinho A. The self-nonself discrimination and the nature and acquisition of the antibody repertoire. Ann Immunol (Paris) 1980;131D:235-53
4. Coutinho A, Forni L, Holmberg D, Ivars F. Is the network theory tautologic? In: Möller E, Möller G, eds. Nobel Symposium 55: genetics of the immune response. New York: Plenum Press, 1984 (in press)

5. Watson J, Kelly K, Largen M, Taylor BA. The genetic mapping of a defective LPS response gene in $\mathrm{C} 3 \mathrm{H} / \mathrm{HeJ}$ mice. J Immunol 1978;120:422-4

6. Coutinho A, Meo T. Genetic basis for unresponsiveness to lipopolysaccharide in $\mathrm{C} 57 \mathrm{BL} / 10 \mathrm{Cr}$ mice. Immunogenetics 1978;7:17-24

7. Coutinho A, Forni L, Watanabe T. Genetic and functional characterization of an antiserum to the lipid A-specific triggering receptor on murine B lymphocytes. Eur $\mathbf{J}$ Immunol 1978;8:63-7

8. Martinez-A C, Coutinho A. B-cell activation by helper cells is a two-step process. Nature 1981;290:60-1

9. Pobor G, Pettersson S, Bandeira A, Martinez-A C, Coutinho A. B lymphocyte activation upon exclusive recognition of major histocompatibility antigens by $\mathrm{T}$ helper cells. Eur J Immunol, 1984;3:222-7

10. Martinez-A C, Coutinho A, Bernabé RR, Augustin A, Haas W, Pohlit H. Hapten-specific helper T cells. I. collaboration with $B$ cells to which the hapten has been directly coupled. Eur J Immunol 1980;10:403-10

11. Leanderson T, Lundgren E, Ruuth E, Borg H, Persson H, Coutinho A. B-cell growth factor: distinction from T-cell growth factor and B-cell maturation factor. Proc Natl Acad Sci (USA) 1982;79:7455-9

12. Pettersson S, Pobor G, Bandeira A, Coutinho A. Distinct helper activities control growth or maturation of $\mathrm{B}$ lymphocytes. Eur J Immunol 1983;13:249-54

13. Leanderson T, Pettersson S. Characterisation of activities inducing polyclonal maturation of activated $B$ lymphocytes to immunoglobulin secretion. Eur J Immunol, 1984 (in press)

14. Lemke H, Coutinho A, Opitz H-G, Gronowicz E. Macrophages suppress direct B-cell activation by lipopolysaccharide. Scand J Immunol 1975;4:707

15. Persson UCI, Hammarström LLG, Smith CIE. Macrophages are required for the dextran-sulphate induced activation of B lymphocytes. J Immunol 1977;119:113844

16. Howard M, Kessler S, Chused T, Paul WE. Long-term culture of normal mouse B lymphocytes. Proc Natl Acad Sci (USA) 1981;78:5788-92

17. Bandeira A, Pobor G, Pettersson S, Coutinho A. Differential macrophage requirements for $T$ helper cell and $T$ helper cell-induced B lymphocyte proliferation. J Exp Med 1983;157:312-23

18. Corbel C, Melchers F. Requirement for macrophages or for macrophage-or $\mathrm{T}$ cell-derived factors in the mitogenic stimulation of murine B lymphocytes by lipopolysaccharides. Eur J Immunol 1983;13:528-33

19. Fernandez C, Severinson E. The polyclonal lipopolysaccharide response is accessory-cell-dependent. Scand $\mathbf{J}$ Immunol 1983;18:279-89

20. Dickler HB, Sachs DH. Evidence for identity or close association of the $\mathrm{Fc}$ receptor of $\mathrm{B}$ lymphocytes and alloantigens determined by the $I r$ region of the $H$-2 complex. J Exp Med 1974;140:779

21. Forni L, Pernis B. Interactions between Fc receptors and 
membrane immunoglobulins on B lymphocytes. In: Seligmann M, Preud'homme JL, Kourilsky FM, eds. Membrane receptors of lymphocytes. Amsterdam: North-Holland Publishing, 1975:193-201

22. Forni L, Coutinho A. Receptor interactions on the membrane of resting and activated B cells. Nature 1978;273: $304-6$

23. Sitia R, Rabellino EM, Sockell M, Hämmerling U. A spatial association between membrane IgD and the receptor for $\mathrm{C} 3 \mathrm{~b}\left(\mathrm{CR}_{1}\right)$ at the cell surface of murine $\mathrm{B}$ lymphocytes. J Immunol 1981;126:107-12

24. Forni L. Interactions between immunoglobulins and Iregion antigens on $\mathrm{B}$ lymphocyte membrane. Eur $\mathrm{J}$ Immunol 1984 (in press)

25. Coutinho A, Forni L, Bernabé RR. The polyclonal expression of immunoglobulin variable region determinants on the membrane of B cells and their precursors. Springer Sem Immunopathol 1980;3:171-211

26. Rahmsdorf HJ, Mallick U, Ponta H, Herrlich P. A Blymphocyte-specific high-turnover protein: constitutive expression in resting $B$ cells and induction of synthesis in proliferating cells. Cell 1982;29:459-68

27. Andersson J, Bullock WW, Melchers F. Inhibition of mito- genic stimulation of mouse lymphocytes by anti-mouse immunoglobulin antibodies. I. Mode of action. Eur $\mathbf{J}$ Immunol 1974;4:715-22

28. Niederhuber JE, Frelinger JA, Dugan E, Coutinho A, Shreffler DC. Effects of anti-Ia serum on mitogenic responses. I. Inhibition of the proliferative response to B cell mitogen, LPS, by specific anti-la-sera. J Immunol 1975; 115:1672-6

29. Forsgen S, Pobor G, Coutinho A, Pierres M. The role of I$\mathrm{A} / \mathrm{E}$ molecules in $\mathrm{B}$ lymphocyte activation. I. Inhibition of lipopolysaccharide-induced responses by monoclonal antibodies. J Immunol, 1984 (in press)

30. Forni L, Bernabé RR, Martinez-A C, Coutinho A. Effect of anti- $d$ antibodies on clonal expansion and maturation of B lymphocytes. Immunobiol 1981;160:159-72

31. Augustin AA, Coutinho A. Specific T helper cells that activate $B$ cells polyclonally: in vitro enrichment and cooperative function. J Exp Med 1980;151:587

32. Andersson J, Coutinho A, Melchers F, The role of immunoglobulin in the induction of B lymphocytes. In: Pernis B, Vogel HJ, eds. Cells of immunoglobulin synthesis. New York: Academic Press, 1979:209-21 